\title{
As dimensões do trabalho do "bom professor" nas concepções dos jovens do Ensino Médio
}

\author{
The dimensions of "good teacher" work in the conceptions of young \\ people of High School
}

\section{Las dimensiones del trabajo del "bun profesor" en las concepciones de los jóvenes de la Enseñanza Medio}

\author{
Silvana Soares de Araújo Mesquita ${ }^{1}$ \\ https://orcid.org/0000-0003-0352-2202
}

\begin{abstract}
Resumo: Este artigo tem como protagonistas os jovens da periferia de uma escola de ensino médio com o objetivo de identificar suas concepções sobre o "bom professor". Buscam-se respostas para duas questões: Quais as características apontadas pelos alunos que não podem faltar em um "bom professor" de ensino médio? Quais os objetivos dos jovens, em relação ao ensino médio, que caracterizam tais escolhas? Parte-se da ideia de que é a partir do sentido que os alunos dão ao ensino que eles escolhem seus "bons professores". São apresentados dados de pesquisa qualitativa realizada em uma escola de ensino médio pública na periferia da cidade do Rio de Janeiro. Os dados foram produzidos através da aplicação de questionários junto a 341 alunos do $3^{\circ}$ ano do ensino médio regular e da observação das aulas. As indicações de "bom professor" são categorizadas nas dimensões estratégicas, relacionais, pessoais e motivacionais em relação ao trabalho docente. Os jovens apontam o caráter motivacional dos professores como elemento capaz de conferir sentido para escola de ensino médio. Constata-se que tais indicadores de "bom professor" podem contribuir para a compreensão do trabalho docente e identificação dos saberes necessários para a consolidação da profissão. Palavras-chave: Bom Professor. Ensino Médio. Juventude. Dimensões. Trabalho Docente
\end{abstract}

Abstract: This article has as protagonists young people from the periphery of a high school with the objective of identifying their conceptions about the "good teacher". We seek answers to two questions: What are the characteristics pointed out by students that can not be lacking in a "good teacher" of high school? What are the goals of young people in relation to high school, which characterize such choices? It starts from the idea that it is from the sense that students give to teaching that they choose their "good teachers". Data are presented qualitative research carried out in a public high school in the outskirts of the city of Rio de Janeiro. The data were produced through the application of questionnaires to 341 students of the 3 rd year of regular high school and the observation of classes. The indications of "good teacher" are categorized in the strategic, relational, personal and motivational dimensions in relation to the teaching work. The young people point out the motivational character of the teachers as an element capable of giving meaning to high school. It is observed that such indicators of "good teacher" can contribute to the understanding of the teaching work and identification of the knowledge needed to consolidate the profession.

1 Professora do Departamento de Educação da PUC-RJ da área de Didática, Currículo e formação de professores.

E-mail: silvanamesquita@puc-rio.br 
Keywords: Good Teacher. High School. Youth. Dimensions. Work Theacher.

Resumen: Este artículo tiene como protagonistas a los jóvenes de la periferia de una escuela de enseñanza media con el objetivo de identificar sus concepciones sobre el "buen profesor". Se buscan respuestas para dos cuestiones: ¿Cuáles son las características apuntadas por los alumnos que no pueden faltar en un "buen profesor" de enseñanza media? ¿Cuáles son los objetivos de los jóvenes, en relación a la enseñanza media, que caracterizan tales elecciones? Se parte de la idea de que es a partir del sentido que los alumnos dan a la enseñanza que ellos eligen a sus "buenos profesores". Se presentan datos de investigación cualitativa realizada en una escuela de enseñanza media pública en la periferia de la ciudad de Río de Janeiro. Los datos fueron producidos a través de la aplicación de cuestionarios junto a 341 alumnos del $3^{\circ}$ año de la enseñanza media regular y de la observación de las clases. Las indicaciones de "buen profesor" se clasifican en las dimensiones estratégicas, relacionales, personales y motivacionales en relación al trabajo docente. Los jóvenes apuntan el carácter motivacional de los profesores como elemento capaz de conferir sentido a la escuela secundaria. Se constata que tales indicadores de "buen profesor" pueden contribuir a la comprensión del trabajo docente e identificación de los saberes necesarios para la consolidación de la profesión.

Palabras clave: Buen Profesor. Escuela Secundaria. Juventud. Dimensiones. Trabajo Docente.

\section{INTRODUÇÃO}

A prática pedagógica dos professores é sempre um dos maiores desafios da profissão diante da complexidade do ensino em qualquer fase do processo de ensino-aprendizagem. No entanto, cada segmento de ensino possui um conjunto de especificidades que direcionam o fazer docente diante das expectativas dos próprios alunos, quanto aos objetivos em relação à escola e ao próprio futuro. Este artigo tem como protagonistas os jovens da periferia de uma escola de ensino médio com o objetivo de identificar suas concepções sobre o "bom professor" em relação a sua pratica pedagógica. Buscam-se respostas para duas questões: Quais a características apontadas pelos alunos que não podem faltar em um bom professor de ensino médio? Quais os objetivos dos jovens, em relação ao ensino médio, que caracterizam tais escolhas? Parte-se da ideia de que é a partir do sentido que os alunos dão ao ensino que eles escolhem seus "bons professores".

Por se tratar de análises resultantes de uma pesquisa qualitativa, o uso do termo "bom professor" se evidenciou como uma categoria nativa, trazida pelos alunos investigados ao indicarem os docentes que "faziam a diferença" no dia a dia da escola. A opção por adotar a expressão "bom professor" emerge da empiria e do senso comum dos atores investigados, possibilitando o distanciamento da racionalização do fazer dos docentes e da superação de uma visão performática do trabalho, que às vezes se associam às pesquisas sobre desempenho docente. $O$ diferencial desta pesquisa é justamente procurar a efetividade do trabalho docente, reconhecendo os aspectos objetivos e subjetivos das ações dos "bons professores" indicados pelos próprios alunos. 
O uso do adjetivo "bom" não busca fazer um juízo de valor, ou identificar um modelo ideal de professor ou um padrão do superprofessor ${ }^{2}$. O adjetivo "bom" procura delimitar um conjunto de estudos e ideias sobre as formas de se desempenhar a docência, a fim de contribuir com a aprendizagem real dos alunos no contexto atual. Qual o principal papel a ser desempenhado pelo professor no ensino médio na concepção dos alunos? O que os jovens esperam de um professor neste segmento de ensino? Quais as dimensões do trabalho docente são reconhecidas pelos jovens como fundamentais para o processo de ensino- aprendizagem?

A pesquisa foi realizada em uma escola de ensino médio pública localizada na periferia da capital Fluminense. Trata-se de uma instituição de grande porte, com mais de 1.800 jovens matriculados e distribuídos em cerca de 45 turmas no período diurno, no qual a pesquisa foi realizada. Neste universo de alunos, transitam cerca de 85 professores que lecionam exclusivamente no ensino médio. Parte dos dados produzidos foi obtida pela aplicação de questionários com questões abertas a 341 jovens-alunos do $3^{\circ}$ ano do ensino médio regular. Este material possibilitou parte das análises apresentadas aqui, associadas com depoimentos recolhidos no cotidiano escolar e observação das aulas registradas no diário de campo.

No campo educacional evidencia-se uma série de referências metodológicas e teóricas sobre as dimensões da ação pedagógica e o desempenho dos professores. São pesquisas que desde a educação infantil, séries iniciais, ensino médio até a educação superior procuram refletir sobre um perfil profissional e/ou pedagógico que caracterize uma ação docente de qualidade (BRESSOUX, 2003; BROOKE e SOARES, 2008; OCDE, 2005; BRUNS E LUQUE, 2014; PERRENOUD, 2001; FORMOSINHO et al, 2010; TARDIF, 2005)

No entanto, junto com estes estudos, se reconhecem as especificidades das categorias profissionais que se estruturam de acordo com o segmento que o professor atua e do contexto social, político e cultural no qual se dá a atuação docente. Ao se refletir sobre o bom professor do ensino médio em particular é preciso considerar que a "reflexão didática deve ser elaborada a partir da análise de experiências concretas, procurando-se trabalhar continuamente a relação teoria-prática" (CANDAU, 2012, p.16).

Portanto, concretiza-se a proposta de identificar as características de um professor de ensino médio que conferem efetividade ao ensino, partindo das experiências entre os

$\overline{2}$ Este discurso, predominante na escola de massas, enaltece um professor que pode, apenas pela condição docente e com a vontade inerente a seu espírito de missão, desenvolver uma série cada vez mais alargada de trabalhos que extravasam a sala de aula e pode desempenhar múltiplas funções na escola (FORMOSINHO, 2009). 
pares. Mas, quais os principais envolvidos na ação docente no ensino médio, ou seja, quem poderia opinar sobre o fazer e o desempenho destes professores? Opta-se pela participação dos jovens, público alvo da escola média.

A educação e, por conseguinte, a docência recebem muitas influências externas, principalmente, por ser um processo pelo qual passa a grande maioria dos cidadãos. Cada pessoa constrói um modelo de professor ideal, resultado de suas experiências escolares e de suas concepções de qualidade.

Dentro do grupo das pesquisas empíricas e das várias vertentes que são adotadas para estudar o trabalho dos professores e seu desempenho, este artigo se baseia no protagonismo dos jovens envolvidos na ação docente e na interpretação de suas concepções no contexto escolar.

Os nossos bons professores são os melhores dentro de uma concepção de educação, de ensino e de aprendizagem. Se essas concepções forem alteradas, o conceito de bom professor certamente também o será (CUNHA, 1996, p.150).

\section{A PARTICIPAÇÃO DOS JOVENS NA PESQUISA}

Estudos sobre juventude (CARRANO E DAYRREL, 2014; DAYRELL, 2007; ABRAMO e BRANCO, 2005; SPOSITO, 1997, 2005; DUBET, 2006) tem mostrado que a ensino médio precisa valorizar o protagonismo juvenil, levando em conta seus interesses e expectativas. Para Fanfani (2000), a escola média não foi instituída para os novos jovens que chegam até ela, fruto de uma nova morfologia social e de novas culturas que entram em choque com a tradição escolar e com os próprios docentes, desencadeando contradições e desencantos.

Considerara a participação dos jovens em estudos sobre a prática docente permite superar o antigo modelo educacional, altamente hierarquizado, centralizado, burocrático e dominante. As escolas podem com isso, passar a ser considerada como organizações mais participativas e autônomas, a fim de atender as novas demandas contemporâneas caracterizadas pelo domínio das tecnologias, pelo aligeiramento das informações e pela heterogeneidade cultural.

O aluno da escola de ensino médio precisa ser reconhecido como jovem dotado de um conjunto de especificidades próprio desta fase de desenvolvimento e, ao mesmo tempo, de heterogeneidade devido à diversidade cultural que marca sua origem social. A juventude que adentra a escola de ensino médio, via sua expansão, precisa ser ouvida sobre os seus anseios, o sentido que dão à escola e interpretar suas indicações sobre as características de um "bom professor" pode contribuir na legitimação de uma escola média mais efetiva. 
Para Dubet (2002), a decadência tanto do programa institucional, quanto da definição clara dos papéis desempenhados dentro da escola (ofício do professor, ofício do aluno, ofício do gestor), permite que se questione o poder de socialização das instituições, seus métodos e modelos e se aponte os sujeitos como uma parte importante deste novo processo.

Os jovens que participaram desta pesquisa, apesar da heterogeneidade de trajetórias escolares, gostos e manifestações culturais, as suas condições juvenis se assemelha quanto ao contexto territorial no qual se inserem. São jovens que residem em uma região periférica de uma das maiores capitais do país, marcada pela violência urbana, que convivem com a dificuldade de acesso aos serviços públicos como saúde; abastecimento de água regular; a coleta de lixo é precária; a mobilidade urbana é comprometida pela alta densidade demográfica da região e pelo sistema de transporte urbano superlotado, além disso 0 acesso às atividades de lazer e culturais é restrito.

No que tange aos sentidos atribuídos a escola pelos sujeitos desta pesquisa, há divergências, tanto entre os próprios jovens, quanto principalmente com os objetivos do ensino médio. Estudos semelhantes (CHARLOT, 1996; DUBET, 2002; REIS, 2012; BRENNER E CARRANO, 2014) já apontam que os jovens que acessam a escola de ensino médio público, destinada às massas, possuem relações divergentes com o conhecimento legitimado pela mesma ao longo dos anos. Constata-se que os jovens de classe populares chegam à escola questionando a validade dos saberes ensinados. Trata-se de perspectivas divergentes, ou até mesmo ausentes, em relação ao futuro que almejam.

Entre os jovens da escola investigada identifica-se a formação de grupos marcada pelas diferenças e contrastes culturais encontrados no meio. Assim, o valor do conhecimento entre os jovens também é marcado pela diversidade. Alguns valorizam uma lógica instrumental do ensino. O conhecimento valorizado é o que tem aplicação direta e prática, que possa explicar o cotidiano ou contribuir no acesso profissional. Outro grupo de jovens demonstra valorizar o pensamento reflexivo, questionam a origem e o porquê das coisas e se interessam pelas disciplinas de Filosofia e Sociologia. Este grupo solicita em suas revindicações uma escola média em tempo integral, com uma biblioteca maior e ampliação dos conteúdos ensinados. Um terceiro grupo se destaca ainda por relacionar o conhecimento com as manifestações culturais e artísticas. Estes valorizam a expressão artística por meio de desenhos, pinturas, além da dança e do teatro. Este grupo reivindica atividades extracurriculares, como visitas a museus, palestras e espetáculos culturais como forma de acessar este conhecimento via escola.

Identifica-se que a mobilização para frequentar a escola de ensino médio é algo automático na vida desses jovens, ligada a uma obrigação social e a uma aposta na escola 
para sua ascensão social. Porém, após sua entrada, os conflitos com os saberes escolares e os aparentes desencontros com os múltiplos objetivos de vida de cada jovem, levam a um desencontro com a escola e à busca de outros sentidos para ela. A ênfase na sociabilidade presente nas relações com os colegas e com os próprios professores passa a ser um dos maiores sentidos que os jovens atribuem à escola.

Chama atenção a pouca relação estabelecida pelos jovens estudados entre escola, conhecimento e saber. Não se evidencia uma valorização da busca pelo conhecimento simplesmente ou do prazer de estudar e aprender. Assim, se tomarmos as ideias de Charlot (1996), de que as relações com o saber são construções sociais, isto é, construídas tanto a partir das experiências do mundo cotidiano quanto das experiências escolares, torna-se um desafio compreender como a escola média se distanciou dos sentidos atribuídos ao saber pelos alunos da periferia.

Por conseguinte, a maioria dos jovens da pesquisa questiona de alguma forma os conhecimentos selecionados pela escola e demonstram certo desencanto pelo ensino. Como afirma Canário (2006), a escola das promessas passa a ser vista como uma escola de incertezas. Então, como articular os saberes científicos e escolares com os saberes destes jovens e o valor que atribuem à escola? Os próprios alunos parecem dar a respostas:

É somente o professor que pode fazer eu me interessar pela matéria (Aluno do $3^{\circ}$ ano). É o professor que me mostra o porquê do aprender (Aluno do $3^{\circ}$ ano)

Assim, parece haver um eixo comum que pode ampliar a questão do sentido da escola para estes jovens pesquisados: o papel central dos professores. A maioria dos alunos afirma ser o professor o elemento que pode dar sentido ao ato de aprender.

Trata-e de uma grande responsabilidade atribuída aos professores e às práticas pedagógicas adotadas pelos estudantes da periferia. Quais características os jovens identificam nos professores que conseguem desempenhar este papel? Como são as práticas dos professores, identificadas pelos alunos, que fazem a diferença para aprendizagem?

\section{As principais dimensões do trabalho docente na opinião dos alunos}

Um total de 341 alunos do $3^{\circ}$ ano do ensino médio (cerca de $80 \%$ do total de alunos desta série) respondeu a um questionário que possibilitou a reflexão sobre as características de um "bom professor" de ensino médio. Este foi construído com nove questões abertas com o objetivo do questionário de obter a indicação dos bons professores por parte dos alunos e seus critérios. As perguntas favoreciam, inicialmente, as reflexões dos alunos sobre a própria escola e suas expectativas em relação ao ensino. Depois, foram exploradas 
as opiniões dos jovens sobre uma boa aula, o que esperavam de um professor e, ainda, suas principais dificuldades para aprender. Por fim, o aluno precisava enumerar as características de um bom professor e indicar quais de seus professores se encaixavam nelas.

Realizaram-se dois movimentos de tabulação dos dados: O primeiro de reunir as características indicadas pelos alunos em relação a um bom professor, a partir da leitura de todas as respostas dos questionários. Identificou-se que os 341 alunos utilizaram 115 palavras/expressões diferentes para caracterizar o trabalho do professor, estas receberam 1.831 indicações dos participantes, o que confere uma média de seis argumentações diferentes por aluno. Utilizando o aplicativo nuvem de palavra ${ }^{3}$ foi possível construir os diagramas (1 e 2), no qual quanto maior o tamanho da letra da palavra/expressão, maior o número de referências da mesma no texto analisado (no caso, as respostas dos alunos ao questionário).

O segundo movimento foi de agrupamentos das ideias identificando uma série de pontos comuns entre as indicações e a possibilidade de construção de algumas categorias que serão apresentadas a seguir. É preciso deixar claro que os limites entre as categorias/ dimensões propostas são flexíveis e estas foram construídas, principalmente, para possibilitar uma análise mais precisa e pontual dos dados.

O diagrama 1 mostra as expressões usadas pelos alunos para definir um bom professor e suas aulas. Evidencia-se uma unanimidade nas afirmações dos alunos de que o bom professor "explica bem" ou "ensina bem". São identificados 142 alunos (41,64\%) que utilizam uma destas duas expressões para definir o bom professor.

Diagrama 1: Expressões usadas pelos alunos para definir um bom professor e suas aulas

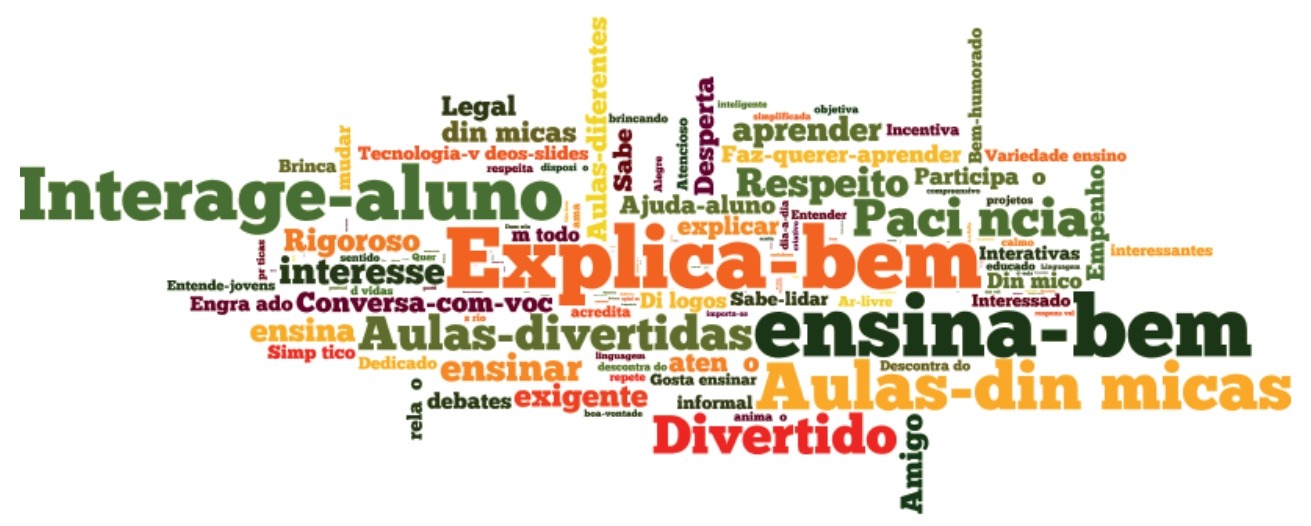

Fonte: Elaborado pela autora a partir dos questionários dos alunos

3 Uma nuvem de palavras é um rcurso gráfico (usado principalmente na internet) para descrever os termos mais frequentes de um determinado texto. O tamanho da fonte em que a palavra é apresentada é uma função da frequência da palavra no texto: palavras mais frequentes são desenhadas em fontes de tamanho maior, palavras menos frequentes são desenhadas em fontes de tamanho menor. Disponível em http://www.uff.br/cdme/lpp/lpp-html/lpp-d-br.html. Acesso em 13 de julho de 2015. 
O que significa isso?

Identificou-se que somente pela análise das demais características apontadas se poderia interpretar melhor o que os alunos consideram "ensina bem/explica bem". Construiu-se, então, o diagrama 2, novamente, com todas as expressões citadas pelos alunos, porém retirando os termos "explica bem", "ensina bem", "sabe ensinar" e "ensina direito".

Com a adoção dessa estratégia, destacaram-se os termos: aulas-dinâmicas, interage-aluno, paciência, divertido e aulas-divertidas. Dessa forma, identificou-se que tais expressões pareciam inscrever o trabalho docente, na visão dos alunos, em quatro dimensões que caracterizavam o "bom professor". Optou-se por nomeá-las de dimensões: estratégica, pessoal, relacional e motivacional. Em cada uma destas foram agrupadas, por aproximação, as indicações dos alunos pesquisados, identificando ainda subcategorias, descritas a seguir.

Diagrama 2: Expressões usadas pelos alunos para definir um bom professor e suas aulas, retirados os termos"explica bem", "ensina bem", "sabe ensinar" e "ensina direito"

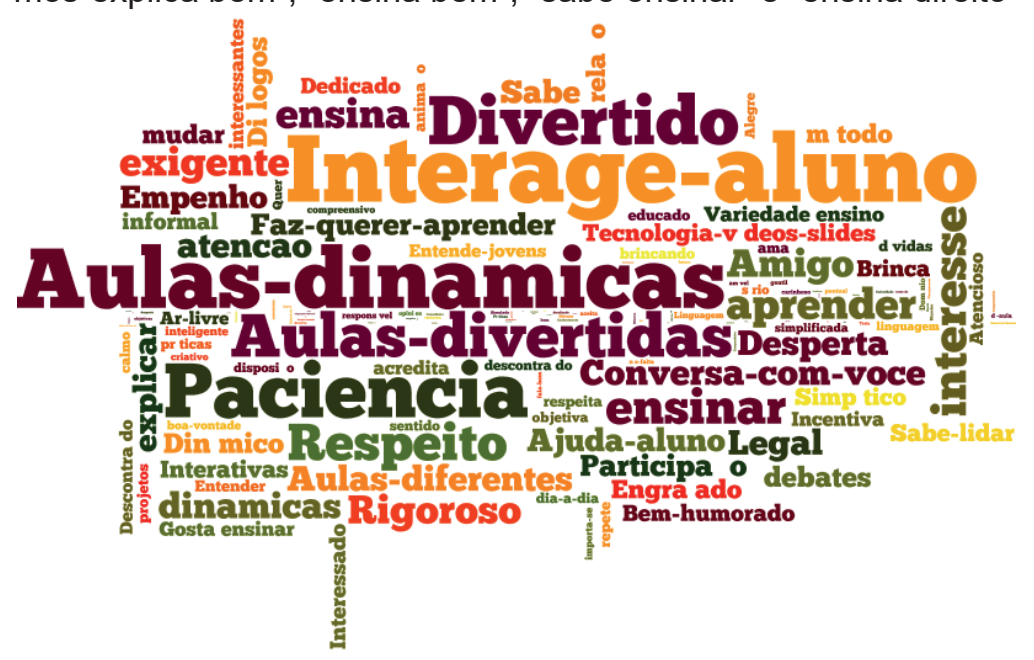

Fonte: Elaborado pela autora a partir dos questionários dos alunos

As escolhas e nomeação de cada dimensão se deram pela associação de duas ideias: o conceito de Didática Fundamental (CANDAU, 1983; 2012) e os achados empíricos. Para Candau (2012), a Didática precisa superar a visão instrumental e de neutralidade que prevaleceu por muitos anos, adotando uma concepção multidimensional e contextualizada com a realidade que considere as dimensões humanas, técnica e político-social do processo ensino-aprendizagem. Além disso, os alunos, ao analisarem a prática de seus professores, incorporaram ainda elementos em relação à identidade e à personalidade dos docentes como fundamentais ao processo ensino-aprendizagem. Assim, as dimensões pedagógicas do trabalho docente superam uma visão meramente instrumental e incorporam elementos subjetivos e até sociais. 


\subsection{Dimensão estratégica}

A dimensão estratégica compreende as características de uma boa aula e os recursos metodológicos que os alunos mais associam aos 'bons professores'. O quadro 1 reúne $465\left(27,5 \%^{4}\right)$ indicações de palavras/expressões citadas pelos alunos ao serem questionados sobre as características de um "bom professor" e suas aulas que se relacionam com o tema das estratégias. Assim, esta categoria reúne menções que os alunos fazem às estratégias didáticas e metodológicas que os bons professores utilizam ou que eles próprios concebem como formas de melhorar o processo ensino-aprendizagem.

Quadro 1 - Estratégias didático-pedagógicas valorizadas pelos alunos do ensino médio e identificadas nos seus bons professores.

\begin{tabular}{|c|c|c|c|c|c|}
\hline Estilo das aulas & $\begin{array}{l}\mathrm{N}^{\circ} \text { de } \\
\text { alunos }\end{array}$ & $\begin{array}{c}\text { Formas de } \\
\text { contextualização }\end{array}$ & $\begin{array}{l}\mathrm{N}^{\circ} \text { de } \\
\text { alunos }\end{array}$ & $\begin{array}{c}\text { Recursos estratégicos } \\
\text { específicos }\end{array}$ & $\mathrm{N}^{\circ}$ de alunos \\
\hline Aulas dinâmicas & 85 & $\begin{array}{l}\text { Linguagem clara/ sim- } \\
\text { plificada/ informal }\end{array}$ & 28 & $\begin{array}{l}\text { Tecnologia/vídeos / } \\
\text { slides }\end{array}$ & 24 \\
\hline $\begin{array}{l}\text { Aulas divertidas/ } \\
\text { ensinar brincando }\end{array}$ & 76 & $\begin{array}{l}\text { Aula práticas/úteis/ } \\
\text { com sentido/ objetivas }\end{array}$ & 18 & $\begin{array}{l}\text { Passeios/saídas da } \\
\text { sala de aula }\end{array}$ & 18 \\
\hline $\begin{array}{l}\text { Aulas diferentes/ } \\
\text { diferenciadas }\end{array}$ & 35 & $\begin{array}{l}\text { Aulas informais/ leves/ } \\
\text { Descontraídas }\end{array}$ & 14 & Dinâmicas & 36 \\
\hline $\begin{array}{l}\text { Aulas atrativas/ } \\
\text { interessantes }\end{array}$ & 25 & Exemplos do dia a dia & 14 & $\begin{array}{l}\text { Variedade nas formas } \\
\text { de ensinar }\end{array}$ & 25 \\
\hline $\begin{array}{l}\text { Aulas interativas/ } \\
\text { com diálogo }\end{array}$ & 23 & & & Projetos & 15 \\
\hline $\begin{array}{l}\text { Criatividade /inova- } \\
\text { ção }\end{array}$ & 15 & & & $\begin{array}{l}\text { Mudar método de } \\
\text { ensino }\end{array}$ & 14 \\
\hline
\end{tabular}

Fonte: Elaborado pela autora.

Ficaram evidenciadas três subcategorias quanto às estratégias, sendo que a primeira reúne os estilos de aulas mais valorizados pelos alunos. São aulas com 'movimento', nas quais os alunos são sujeitos ativos e não meros expectadores, os alunos querem fazer parte das aulas e, para isso, dizem os alunos, o seu professor precisa fazer diferente, buscar inovações e criatividade, a fim de tornar o ensino interessante e atrativo.

Novamente fica evidenciada a questão da busca por sentido para a experiência escolar dos jovens no ensino médio regular público. Os alunos de classes populares que chegaram ao ensino médio rejeitam o modelo tradicional, propedêutico, enciclo-

4 Os percentuais calculados em cada dimensão consideraram o total de 1831 indicações dadas pelos alunos para as características de um bom professor, retirando as 142 indicações das expressões explica-bem e ensina- bem. Assim, o total considerado foi de 1689 indicações. 
pédico, pensado inicialmente para as elites, mas que não serve para eles, naquele momento.

São os próprios alunos que dizem como se pode superar esse desencontro, com contextualização e estratégias didáticas variadas. Na subcategoria "formas de contextualização" os alunos deixam claro que a linguagem do professor é ponto central para que o processo de ensino aconteça de forma significativa. As aulas precisam fazer sentido para a vida que eles conhecem.

No entanto, chama atenção esse sentido de 'utilidade' dado ao ensino por parte dos alunos e o risco do excesso de pragmatismo que o ensino pode tomar. Os limites de aproximação entre teoria e prática são sempre um dos grandes debates no meio acadêmico e não se restringem apenas aos cursos profissionalizantes ou de formação em nível superior. A defesa pela contextualização dos conteúdos do ensino médio entrou em pauta desde as novas orientações para o ensino médio, definidas na LDB 9394/96, e vem sendo priorizada no PCNEM - Parâmetros Curriculares Nacionais do Ensino Médio (BRASIL, 1999), nos PCN +, Parâmetros Curriculares Nacionais Mais (BRASIL, 2002), na Matriz de Referência do Enem (BRASIL, 2009) e nas atuais DCNEM - Diretrizes Curriculares Nacionais do Ensino Médio (BRASIL, 2012).

A adoção do termo contextualização não pode ser compreendida como aligeiramento dos conteúdos, reducionismo ou simplificação conceitual. Contextualizar é permitir a significação dos conhecimentos científicos em diálogo com os contextos culturais e sociais diversos. Para isso, precisam ganhar destaque as novas formas de organizar e abordar os conteúdos no ensino médio.

Para os alunos pesquisados, os recursos estratégicos específicos que se destacam no processo de ressignificação do currículo são marcados pela variedade nos métodos, com ênfase na realização de dinâmicas e projetos. O uso de equipamentos tecnológicos e de aulas passeios até aparece nas indicações dos alunos, mas não de forma tão expressiva quanto à questão da interação e da participação.

Aula boa é quando o professor não fica só escrevendo e falando a aula inteira e sem interagir com os alunos. (Aluno da turma 3008)

Se eu fosse professor eu faria aulas dinâmicas que levassem os alunos a se envolver mais com a matéria. (Aluno da turma 3007)

Bom professor é o que não fica só enchendo o quadro de texto para a gente copiar. (Aluno da turma 3010) 


\title{
2. 2 Dimensão pessoal
}

A seleção das características agrupadas na dimensão pessoal parte do pressuposto de que são características ligadas à personalidade do professor. Da mesma forma que os alunos a evidenciaram, os estudos de Dubet $(1994,1997,2002)$ sobre juventude e escola média francesa também concluem que a personalidade dos professores marca muito o seu trabalho.

\begin{abstract}
A pedagogia é uma técnica da operacionalização da personalidade. Quando se pede a um professor para mudar o seu método, não se pede apenas que ele mude de técnica, pede-se para que ele próprio mude. E, no fundo, a gente vê muito bem o tipo de sabedoria professoral, que não é um absurdo, quando os professores dizem: 'Existem métodos que me servem e métodos que não me servem' (...) $E$, aliás, os alunos são muito sensíveis a este tipo de adequação da personalidade do professor e de seu estilo pedagógico (DUBET,1997, p. 226).
\end{abstract}

No quadro 2 as características pessoais que mais se destacaram foram agrupadas em duas subcategorias, atitudes pró-ativa e pessoal-relacional. Foram reunidas 390 $(23,1 \%)$ indicações de palavras/expressões relacionadas com esta dimensão.

Quadro 2 - Características pessoais identificadas pelos alunos em seus bons professores.

\begin{tabular}{|l|c|l|c|}
\hline Atitudes pró-ativa & $\begin{array}{l}N^{0} \text { de } \\
\text { alunos }\end{array}$ & Pessoal-relacional & $\begin{array}{l}N^{\circ} \text { de } \\
\text { alunos }\end{array}$ \\
\hline Divertido & 69 & Paciência para ensinar & 67 \\
\hline Legal & 40 & & \\
\hline Dinâmico & 28 & Educado/gentil & 21 \\
\hline Brincalhão na hora certa & 23 & & \\
\hline Bem humorado & 23 & Atencioso & 19 \\
\hline Descontraído/extrovertido & 18 & & 24 \\
\hline Animação-animado & 16 & Simpático & \\
\hline Engraçado & 14 & & 14 \\
\hline Alegre-feliz & 14 & Calmo/tranquilo & \\
\hline
\end{tabular}

Fonte: Elaborado pela autora.

Nas atitudes pró-ativas reuniram-se 245 indicações ligadas a um estilo ativo do professor, desejado por parte dos alunos e reconhecidos em seus bons professores, como legal, divertido, dinâmico. $\mathrm{O}$ aluno rejeita um professor passivo e insatisfeito, autoritário ou sério demais.

Professor tem que ser falador, carismático e engraçado (Aluno da turma 2016).

Professor é divertido, sabe a hora de falar sério e sabe a hora de abordar com brincadeiras (Aluno da turma 2007). 
Algumas características pessoais se mostram associadas com a busca por participação/interação que os alunos vêm apontando desde a categoria estratégia. Assim, as indicações, paciente, educado, gentil, calmo, simpático e atencioso foram reunidas no eixo pessoal-relacional por serem consideradas pelos alunos pré-requisitos para o estabelecimento da relação professor-aluno, com vistas à aprendizagem. Segundo Monteiro e Martins (2009), para o professor "afastar-se disso é negar o seu próprio trabalho!".

Identifica-se que alguns professores parecem não conseguir desenvolver este papel de envolvimento de sua personalidade com o ofício, de subjetivação e de ensino. Primeiro porque, historicamente, a autoridade do professor e o respeito dos alunos por sua pessoa era algo já dado, legitimado pelo papel que a escola como santuário ocupava na sociedade (DUBET, 2002). Segundo, porque sua formação inicial e trajetória profissional são marcadas pela ideia equivocada de neutralidade da prática pedagógica, de que o não envolvimento é o que o torna um profissional. No entanto, como afirma Cunha (1996) em estudo sobre o "bom professor", a forma de ser e de agir do professor revela um compromisso e é esta forma de ser que demonstra, mais uma vez, a não neutralidade do ato pedagógico.

\subsection{Dimensão Relacional}

A dimensão relacional agrupa (quadro 3) as características do "bom professor" ligadas à relação com os alunos na escola, com destaque para a expressão "interage com o aluno". São reunidas $467(27,5 \%)$ indicações de palavras/expressões relacionadas com esta dimensão. O favorecimento do diálogo, da participação e dos debates sintoniza com as características estratégicas de aulas dinâmicas e interativas. Segundo Candau (1983), as relações interpessoais compreendem a dimensão humana da didática configurando-se como o centro do processo de ensino, sendo superior ao valor da técnica. Porém, tais relações precisam ser articuladas com as dimensões política-social e técnica da didática para não prevalecer uma visão humanista unilateral e reducionista que priorize apenas as relações afetivas.

Quadro 3 - Características relacionais identificadas pelos alunos em seus bons professores.

\begin{tabular}{|l|c|l|l|l|c|}
\hline Interação & $\begin{array}{l}\mathbf{N}^{\circ} \text { de } \\
\text { alunos }\end{array}$ & Gestão de classe & $\begin{array}{l}\mathbf{N}^{\circ} \text { de } \\
\text { alunos }\end{array}$ & Cuidado & $\begin{array}{l}\mathbf{N}^{\circ} \text { de } \\
\text { alunos }\end{array}$ \\
\hline Interage com o aluno & 95 & $\begin{array}{l}\text { Com regras/ exigente/ } \\
\text { limite-disciplina }\end{array}$ & 40 & $\begin{array}{l}\text { Trata com respeito/ } \\
\text { bem }\end{array}$ & 62 \\
\hline $\begin{array}{l}\text { Conversa com o aluno/ } \\
\text { comunicativo }\end{array}$ & 36 & & Amigo & 41 \\
\hline
\end{tabular}




\begin{tabular}{|l|c|l|c|l|c|}
\hline $\begin{array}{l}\text { Participação aluno/ } \\
\text { troca/ouve }\end{array}$ & 36 & $\begin{array}{l}\text { Sabe lidar com os alunos/ } \\
\text { domínio da turma }\end{array}$ & 32 & $\begin{array}{l}\text { Ajuda o aluno/ colabo- } \\
\text { ra/compreende }\end{array}$ & 42 \\
\hline $\begin{array}{l}\text { Favorece o diálogo e } \\
\text { os debates }\end{array}$ & 28 & & $\begin{array}{l}\text { Entende os alunos/ } \\
\text { jovens }\end{array}$ & 18 \\
\hline $\begin{array}{l}\text { Relação boa-convivên- } \\
\text { cia }\end{array}$ & 14 & Seriedade quando precisa & 13 & $\begin{array}{l}\text { Importa-se com o } \\
\text { aluno }\end{array}$ & 10 \\
\hline
\end{tabular}

Fonte: Elaborado pela autora.

Os alunos reconhecem no dia a dia, o mesmo que Tardif e Lessard (2005) expõem: "o trabalho docente é uma profissão de interações humanas". Assim também ressalta Dubet (2002), ao afirmar que a docência é um trabalho sobre o outro e, portanto, as relações subjetivas precisam se estabelecer.

A docência não é um trabalho cujo objeto é constituído de matéria inerte ou de símbolos, mas de relações humanas com pessoas capazes de iniciativa e dotadas de uma certa capacidade de resistir ou de participar da ação dos professores (TARDIF E LESSARD, 2005, p.35).

Uma subcategoria das questões relacionais refere-se à gestão de classe. Nela os alunos defendem a disciplina e a ordem, reconhecendo a necessidade do estabelecimento de regras para traçar limites. Afirmam que o bom professor precisa saber gerir sua classe com respeito e seriedade, pois mesmo que seja brincalhão e divertido, "tem hora para tudo".

Esse tom de equilíbrio, que os próprios alunos atribuem à docência, é um elemento que parece ser construído ao longo do exercício da docência, resultado mais da epistemologia da prática do que apenas da formação inicial dos professores. Remete à necessidade dos professores desenvolverem competências reflexivas e críticas, a partir da análise da sua prática e da importância de valorização da experiência. Uma mesma turma reconhece que tem professores que sabem lidar muito bem com a classe, suas incertezas e conflitos, pois conseguem o "domínio da turma", enquanto outros nem conseguem dar aulas.

Segundo Dubet (2002), é o professor que cria regras e o ritmo da classe, que estabelece o clima e a tonalidade. Porém, no ensino médio, os alunos acabam por ter que se adaptar a vários ritmos e regras, uma vez que convivem com a alternância constante entre seus dez ou mais professores semanalmente.

A análise das características relacionais destaca ainda as referências dos alunos à questão do cuidado. Um enfoque que poderia estar longe da educação secundária, pois a infância há muito já se foi, recebe 156 associações à forma de tratamento que recebem dos bons professores, quase a metade dos 341 alunos participantes. O professor amigo tem 
tudo a ver com a fase de vida da adolescência, caracterizada pela valorização e conquista das amizades, agora independentemente da tutela dos pais. E, não dá para não se envolver, pois como afirma Tardif e Lessard (2005) "ensinar é trabalhar com seres humanos, sobre seres humanos, para seres humanos".

Bom professor não é só professor, é amigo (Aluno da turma 2004)

Se os alunos gostam mais do professor, aprendem mais, devido à amizade. (Aluno da turma 2005)

Outro elemento que se destaca na relação professor-aluno é o respeito. Em uma relação marcada pelas interações e pela necessidade desta competência relacional (BARRÈRE, 2002), alguns alunos pedem por mais respeito nas relações, mais tolerância. Talvez por conta das diferenças culturais do novo aluno que chega, da perda do sentido já pronto para a escola, da crise de autoridade dos professores, da necessidade de mobilização/ motivação constante do aluno a favor da escola, há algumas relações professor-aluno que se caracterizam pelo conflito.

Bom humor, paciência, gostar de aula, determinação e mesmo ele sendo professor nunca se achar melhor que os alunos (Aluno da turma 2003).

Educado e que saiba respeitar o aluno como a si próprio, que é legal, menos rígido (Aluno da turma 2003).

Segundo Barrère e Martuccelli (2001), para os jovens as relações pedagógicas se baseiam na comunicação e no respeito, como formas singulares de prazer e de significação da própria aprendizagem.

Seria absurdo dizer que a comunicação substituiu os saberes, embora seja cada
vez mais necessário levar em conta a especificidade e a centralidade da comunica-
ção pedagógica, um dos elementos da relação escolar mais prezados pelos alunos.
As consequências são importantes. A começar pelas modificações que acarretam
na relação com a autoridade, que se torna, antes mesmo de qualquer discussão
acerca de sua legitimidade ou da legitimidade das normas, uma questão de reci-
procidade relacional. Os alunos exigem respeitos horizontais. Para eles, a relação
pedagógica correta tem uma natureza igualitária e supõe um respeito mútuo e um
equilíbrio dos sentimentos (lbid, p.270)

\subsection{Dimensão motivacional}

Nunca a motivação foi tão necessária à educação escolar quanto na atual escola pública de ensino médio regular. Na busca por sentidos para a escola o aluno deposita a responsabilidade de seu sucesso no trabalho do professor. Uma vez que a legitimidade 
da escola se encontra ameaçada pelo insucesso de seus egressos, os alunos, mesmo reconhecendo que a escola tem ligação com futuro e mudança social, não se sentem mobilizados apenas por isso. Assim, os alunos repassam aos professores de ensino médio o desafio de motivá-los para aprender.

É o professor que pode fazer eu me interessar pela matéria. (Aluno da turma 2004).

Assim, os alunos reconhecem que precisam de incentivo para aprender ou de um despertar do interesse para fazê-lo ter prazer em estudar (quadro 4). Segundo os alunos, é pelo grau de envolvimento dos próprios professores que os mesmos conseguem despertar este interesse ou desencadear este processo motivacional nos alunos. Foram reunidas 244 $(14,5 \%)$ indicações de palavras/expressões relacionadas com esta dimensão.

A dimensão motivacional compreende também compromisso e satisfação pela profissão. Os jovens apontam que o compromisso, a dedicação e o interesse do professor pela aprendizagem permitem que o mesmo "faça de tudo para o aluno" aprender. Por isso, uma condição que parece estar associada a este empenhamento por parte dos professores está na satisfação pela profissão, nomeada pelos alunos por "ter prazer pelo que faz" ou "gostar de ensinar".

Quadro 4 - Aspectos motivacionais identificadas pelos alunos em seus bons professores.

\begin{tabular}{|c|c|c|c|c|c|}
\hline Mobilização & $\begin{array}{l}\mathrm{N}^{\circ} \mathrm{de} \\
\text { alunos }\end{array}$ & Compromisso & $\begin{array}{l}\mathrm{N}^{\circ} \mathrm{de} \\
\text { alunos }\end{array}$ & $\begin{array}{l}\text { Satisfação pela } \\
\text { profissão }\end{array}$ & $\begin{array}{l}\mathrm{N}^{\circ} \mathrm{de} \\
\text { alunos }\end{array}$ \\
\hline $\begin{array}{l}\text { Desperta o interesse/ } \\
\text { prende a atenção }\end{array}$ & 35 & $\begin{array}{l}\text { Empenha-se/ faz de tudo } \\
\text { para o aluno aprender/ Preo- } \\
\text { cupado com a aprendizagem }\end{array}$ & 36 & $\begin{array}{l}\text { Gosta de ensinar/ } \\
\text { ama o que faz }\end{array}$ & 37 \\
\hline $\begin{array}{l}\text { Faz-nos ter prazer } \\
\text { em aprender/ gostar/ } \\
\text { querer }\end{array}$ & 30 & & & & \\
\hline $\begin{array}{l}\text { Incentiva o aluno/ } \\
\text { acredita no aluno }\end{array}$ & 17 & $\begin{array}{l}\text { Dedicado/interessado/ dis- } \\
\text { posto a ensinar }\end{array}$ & 35 & $\begin{array}{l}\text { Tem prazer no que } \\
\text { faz }\end{array}$ & 6 \\
\hline $\begin{array}{l}\text { Faz-nos entender a } \\
\text { matéria }\end{array}$ & 16 & & & & \\
\hline $\begin{array}{l}\text { Envolve o aluno/ } \\
\text { conquista }\end{array}$ & 5 & $\begin{array}{l}\text { Repete quantas vezes preci- } \\
\text { sar/ Tira dúvidas/ }\end{array}$ & 30 & & \\
\hline
\end{tabular}

Fonte: Elaborado pela autora.

\section{COMPARAÇÃO E INTERSEÇÃO DAS DIMENSÕES DA PRÁTICA DOCENTE}

A fim de conferir densidade a compreensão do perfil de um "bom professor" por parte dos alunos, realiza-se dois novos movimentos, um de comparação e outro de aglutinação das concepções categorizadas. 
A partir da comparação, busca-se através do número de referências o reconhecimento de quais dimensões são predominantes (quadro 5). Dentre todas as características apontadas pelos alunos sobre o trabalho do professor no ensino médio, qual ou quais são se destacam?

Quadro 5 - Comparativo entre a categoria e subcategoria das características do bom professor na concepção dos alunos e o número de indicações recebidas.

\begin{tabular}{|l|c|l|c|l|c|l|c|}
\hline \multicolumn{1}{|c|}{ Estratégias } & $*$ & \multicolumn{1}{c|}{ Pessoal } & $*$ & Relacional & $*$ & Motivacional & $*$ \\
\hline Estilo das aulas & 259 & Atitudes pró-ativas & 245 & Interação & 209 & Mobilização & 103 \\
\hline $\begin{array}{l}\text { Formas de contextua- } \\
\text { lização }\end{array}$ & 74 & Pessoal-relacional & 145 & $\begin{array}{l}\text { Gestão de } \\
\text { classe }\end{array}$ & 85 & Compromisso & 98 \\
\hline $\begin{array}{l}\text { Recursos didáticos } \\
\text { específicos }\end{array}$ & 132 & & $x$ & Cuidado & 173 & $\begin{array}{l}\text { Satisfação pela } \\
\text { profissão }\end{array}$ & 43 \\
\hline $27,5 \%$ & 465 & $23,1 \% \%$ & 390 & $27,5 \%$ & 467 & $14,5 \%$ & 244 \\
\hline
\end{tabular}

Fonte: Elaborado pela autora.

Em uma análise objetivada e direta do quadro, tendo como referência um conjunto de 1689 indicações dadas pelos alunos, divididas as características mais comuns em quatro dimensões do fazer de um "bom professor", pode-se afirmar que os aspectos estratégicos e relacionais são os que predominam. Destaca-se a importância apontada para o estilo das aulas e a ênfase para a interação professor-aluno, amplamente indicada pelos alunos como condição para um bom processo de aprendizagem.

No entanto, há a opção de analisar as características de forma isolada (quadro 6), linear, sem categorização. Observa-se, neste caso, que entre as seis características de um "bom professor" mais indicadas pelos alunos, cada uma se insere em uma categoria diferente.

Quadro 6: As cinco características de um bom professor mais indicadas pelos alunos do ensino médio.

\begin{tabular}{|l|c|l|}
\hline Características de um bom professor & Indicações & Dimensão inserida \\
\hline Interage com o aluno & 95 & Relacional \\
\hline Aulas dinâmicas & 85 & Estratégia \\
\hline Divertido & 69 & Pessoal \\
\hline Paciência & 67 & Pessoal \\
\hline Aulas divertidas & 51 & Estratégia \\
\hline Respeito & 52 & Relacional \\
\hline
\end{tabular}

Fonte: Elaborada pela autora 
No entanto, a dimensão motivacional parece ficar de fora. Porém, associando essas análises objetivas dos dados com as interpretações das observações do cotidiano da escola, das conversas com os alunos e com o acompanhamento das aulas, chega-se a outras conclusões. Com isso, percebe-se a necessidade de um segundo movimento de interpretação para os dados, por reconhecer que esta análise linear e objetivada não consegue por si só explicar a subjetividade por trás da representação de "bom professor" por parte dos alunos. Portanto, buscando uma interpretação mais densa, propõem-se uma interseção dos dados.

Identifica-se que as dimensões levantadas não funcionam de forma isolada. Na verdade, cada uma delas vai auxiliar a prática pedagógica dos bons professores, mas nenhuma a determina isoladamente. É como se a figura do professor e a sua aula tivessem que ter uma multiplicidade de fatores para favorecer a aprendizagem do aluno. A justificativa para esta constatação vai além da questão das diversidades dos alunos e das culturas que compõem uma sala de aula do ensino médio da escola pública. Um mesmo aluno aponta esta interseção de características na sua concepção de bom professor:

O bom professor é amigo, mas ao mesmo tempo exige e cobra. (Aluno da turma 2004).

Divertido, mas ao mesmo tempo sem dar liberdade demais a alguns alunos (Aluno da turma 2003).

Engraçado, autoritário e que saiba explicar a matéria com paciência. (Aluno da turma 2003).

O que aparentemente seria uma contradição pode ser interpretado como a busca por um conjunto de características que deem conta da multiplicidade de ações que cabe ao professor de ensino médio gerenciar no cotidiano. Qual o limite para que determinada característica não prevaleça sobre as demais? Nenhum professor, ou qualquer agente social hoje, tem seu papel bem definido e limitado. As identidades profissionais e pessoais são múltiplas e acionadas de acordo com as situações. As análises sociológicas mundo contemporâneo apontam esta realidade e buscam superar as dicotomias (DUBET, 2002; ELIAS, 1994; FORMOSINHO, 2009).

Assim, mesmo que se destaque certos perfis/características nas indicações dos alunos, há necessidade de pontos de interseção entre as categorias, além de um elemento condutor que aqui, na concepção do aluno, permita dar sentido à escola, aos conteúdos, à aprendizagem.

Um exemplo de como se estrutura essa interseção "das exigências" para ser um bom professor na concepção dos alunos pode ser visto na frase abaixo: 
O bom professor é aquele que me faz querer aprender (característica motivacional), mas para isso ele precisa interagir com a turma, permitir que o aluno participe para conhecê-lo (característica relacional), precisa também ser alegre, bem humorado (características pessoais) e a sua aula tem que ser dinâmica, diferente, quando a gente não fica copiando do quadro o tempo todo (característica estratégica) (Aglutinação dos relatos dos alunos do $2^{\circ}$ ano elaborada pela autora).

Qual dimensão do trabalho docente seria o fio condutor do processo de ensino-aprendizagem na perspectiva dos alunos?

Identifica-se que nas características estratégicas apontadas pelos alunos nos seus bons professores, a valorização de aulas dinâmicas e criativas se justifica pela necessidade de mobilizações externas para aprender. Percebe-se também que as características pessoais do professor com as quais os alunos mais se identificam estão ligadas à busca por incentivos para aprender. O professor divertido, engraçado, bem humorado, dinâmico, legal é o que faz o aluno aprender, afirmam os jovens pesquisados. O mesmo se identifica na importância dada as relações professor- aluno e a gestão de classe como condições para que o aluno encontre sentido para a escola e o ensino. Pode-se, com isso, perceber a necessidade de motivação como um eixo que perpassa todos os demais.

Este artigo inicia-se com a apresentação dos jovens que adentram a escola pública de ensino médio no novo século e dos desafios de construir um sentido escolar. Assim, as características motivacionais parecem se destacar como o fio condutor na busca por identificar o desempenho de um bom professor. O diagrama 3 procura representar a interpretação construída neste capítulo do perfil do "bom professor" de ensino médio na concepção dos alunos. Trata-se de uma aglutinação das quatro dimensões, estratégica, pessoal, relacional e motivacional, porém tendo a motivação em posição central, funcionando um elo ou um ponto de interseção entre as demais.

Assim, tanto o uso de estratégias variadas na aula, quanto à necessidade de interação professor - aluno e o destaque para certas características pessoais do professor apontadas pelos alunos seriam meios do professor conseguir motivar os alunos para aprender.

Diagrama 4: Representação da interseção entre as dimensões do trabalho de um bom professor

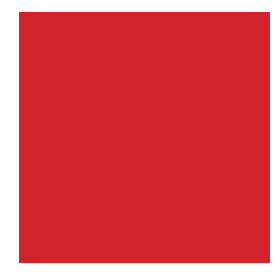

Fonte: Elaborada pela autora 


\section{O QUE FICOU DE FORA?}

Próximo a concluir as análises sobre as concepções dos alunos sobre um "bom professor", merece destaque ainda a interpretação das características pouco mencionadas por parte destes jovens. Acredita-se que analisar as ausências em comparação com outros indicadores/estudos possa contribuir para sua compreensão.

Estudos sobre o surgimento da profissão docente do ensino médio (DUBET, 2002; DIAS, 2008; MENDONÇA, 2013) apontam que o conceito de bom professor surgiu associado aos seus próprios valores morais e a sua postura como pessoa íntegra e honesta. Estas são características não valorizadas pelos alunos hoje.

Além disso, o professor do ensino médio idealizado para as elites (DUBET, 2002) era reconhecido como o erudito, homem de cultura, apaixonado pela sua área disciplinar, que compreendia desde as línguas clássicas até literatura e filosofia. Porém, ao passar para a escola das massas, os professores perdem este reconhecimento. Nesta pesquisa, apareceram apenas 19 referências dos alunos relacionadas ao saber específico dos professores, expressas pelos termos: inteligente (12), conhece o que fala (1), atualizado (3), conhecimento (3). Não há questionamentos, nem positivos nem negativos, ao saber científico dos professores.

As características pessoais ligadas também à postura moral muito exigida do professor do século XIX e início do século XX aparecem apenas na lista de 5 alunos, nas seguintes expressões: sincero, honesto, justo, íntegro. A questão da vocação, citada apenas por dois alunos, também não se evidencia como uma condição para ser bom professor.

Chama atenção como as questões administrativas, ligadas à frequência, pontualidade e cumprimento de prazos por parte dos professores não são evidenciadas pelos alunos em relação ao desempenho do professor. Nem mesmo constatam-se referências às avaliações, notas, reprovações como indicadores do perfil do bom professor.

No entanto, algumas destas questões administrativas e vocacionais serão motivos de críticas e até de critério de caracterização do desempenho do professor por parte de políticas educacionais, relatórios de organismo internacionais, e até da equipe diretora/pedagógica da escola e dos próprios professores entrevistados em outro momento da pesquisa. Portanto, novas dimensões podem ser consideradas de acordo com os sujeitos convidados a refletir sobre as características de um bom professor. É preciso ter claro que tais características se associam principalmente aos objetivos da escola e dos parâmetros de qualidade de ensino adotados. E, como vimos, tem encontrado pontos divergentes, principalmente entre os jovens de classes populares que passaram a acessar a escola média. 


\section{CONSIDERAÇÕES FINAIS}

No intuito de concluir este artigo, retoma-se o debate da relevância de desenvolver um estudo sobre desempenho dos professores partindo dos referenciais dos alunos. Observa-se que, mesmo com o crescimento das pesquisas sobre juventude e o sentido da experiência escolar nas ultimas décadas, poucos são os estudos que buscam entender especificamente as concepções dos alunos em relação ao desempenho do professor como um elemento capaz de elencar estratégias que contribuam na superação da crise do sentido da escola por parte dos jovens, principalmente, das classes populares. Os dados expostos indicam que novas referências sobre o desempenho do professor de ensino médio podem se estruturar a partir do olhar dos alunos, principalmente, no que diz respeito ao caráter motivacional que atribuem aos seus professores e as suas aulas e à importância que conferem às questões relacionais. Tais indicadores de "bom professor" podem contribuir para a compreensão do trabalho docente e identificação dos saberes necessários para a consolidação como profissão.

Por outro lado, destacam-se alguns estudos nesta mesma linha que merecem ser considerados. Em 2009, Moreira e Martins se debruçam sobre o tema e publicam o trabaIho "Quem é o "bom professor" para os estudantes do Ensino Médio?" como parte de uma pesquisa institucional sobre o perfil do bom professor de ensino médio em escolas públicas e privadas no Paraná. Os achados, a partir das concepções dos alunos pesquisados, identificam, mais uma vez, que a dimensão motivacional se destaca, pois o compromisso e a seriedade se sobressaem como características relacionadas à necessidade de motivar os alunos, de fazer o aluno aprender. As autoras também identificam as dimensões pedagógica e pessoal.

Felix (2009), em sua dissertação de mestrado, analisa também as concepções dos alunos de ensino médio sobre bom professor. Esta pesquisa, realizada com 35 alunos da $1^{\text {a }}$ serie do ensino médio do Rio Grande do Sul, identifica que as características ligadas à afetividade e cuidar do outro são as principais norteadoras das concepções dos alunos. A autora observa que

na visão dos alunos o bom professor é aquele que ensina bem, sabe controlar e interage bem com a turma, compreende o aluno, é criativo, responsável, competente, entre outras qualidades. São professores que auxiliam o aluno, uma vez que se colocam disponíveis e como referenciais adultos possíveis para que os alunos adolescentes possam identificar-se (FELIX, 2009).

Oliveira R. J. (2007) desenvolve um estudo no Distrito Federal sobre a percepção de alunos do ensino médio de escola pública sobre o bom professor de Matemática. A autora 
identifica que as características mais recorrentes de um bom professor são de caráter pessoal e relacional, como uma pessoa paciente, atenciosa, bem-humorada e que seja apaixonada pela profissão. "Para os mesmos, uma boa aula de Matemática tem que ter interação professor-aluno em primeiro lugar", relata a autora (OLIVEIRA R. J, 2007).

Esses dados também já apareciam no livro de Maria Isabel Cunha (1996), decorrente dos resultados de sua pesquisa de doutorado sobre o perfil do bom professor. Cunha (1996) constata que, para os alunos pesquisados, o bom professor é aquele que domina o conteúdo, recorre a uma boa didática de ensino e, principalmente, tem um bom relacionamento com a turma.

Assim, sem desprezar os limites de pesquisa com esta abordagem, "concepções dos alunos de bom professor", os achados se aproximam. Os alunos alertam para a importância das relações professor-aluno, para a necessidade de motivação, para adequação do conteúdo ensinado. Entretanto, é quase nula a apropriação destes resultados por parte das políticas de formação de professores e, mais recentemente, nas propostas de avaliação de desempenho docente, na maioria das vezes baseadas nos resultados dos alunos em testes padronizados e em políticas de bonificação (FERNANDES, 2008; RODRIGUES, 2012; NOGUEIRA et al., 2013).

Constata-se nesse distanciamento da academia e dos governos com as escolas e os alunos de ensino médio que, mais uma vez, os sujeitos envolvidos no processo ensinoaprendizagem são deixados de lado. Possibilitar o diálogo entre os saberes escolares e os saberes dos jovens pode se consolidar como mais uma ferramenta de melhoria do ensino médio. O sentido da escola média, mesmo prescrito nas leis e nos currículos, não se consolidará no dia a dia das escolas se forem antagônicos à realidade dos jovens de classes populares. Segundo Reis (2012), não se pode impor um sentido para escola, pois é fundamental compreender o alcance das atividades que a escola propicia aos jovens. Enfatiza-se que "é a escola que tem que ser repensada para responder aos desafios que a juventude nos coloca" (DAYRREL, 2007, p.1107).

Por fim, retoma-se a questão: o que significam as afirmações de que o bom professor "explica bem", "ensina bem", "sabe ensinar" e "ensina direito"?

Diante da diversidade do público pesquisado e apresentado, "ensinar bem" envolve a interlocução das mais de cem características indicadas, reunidas em quatro categorias e subcategorias, somadas às referências não categorizadas por não se evidenciarem. Em resumo, professor que "ensina bem", segundo os alunos, tem o poder de motivá-los para aprender, de dar sentidos aos conteúdos e, consequentemente, à escola. $\mathrm{O}$ bom professor 
parece poder orientar o futuro dos jovens via motivação, interação e personalidade. A centralidade do professor na vida dos jovens é inquestionável para eles.

E qual o papel dos professores diante deste jovem?

Os jovens de ensino médio de classes populares reconhecem o professor como o elemento desencadeador de seu processo de estudo. É como se o docente fosse o "gatilho" para aprendizagem do aluno. O professor na escola de massas tem papel "catalisador", conforme afirma Formosinho (2009).

Diante desse "poder" que Ihes é conferido de "me fazer aprender", será que os professores estão cientes disso? Estão conscientes da importante dimensão que exercem na vida de seus jovens alunos? "Ensinar bem" para os professores tem as mesmas dimensões que para os alunos? Ou ainda, como pode o professor de ensino médio ser tudo isso? Haveria tipos de professores? Os mais motivacionais, os mais interativos, os mais técnicos?

Estas são questões deixadas para reflexões e pesquisas futuras, pois segundo Lessard (2006), talvez o cerne da questão esteja não na formação de professores para a eficiência, mas o desenvolvimento de competências para o professor compreender o que o torna eficiente, dentro de tal situação, com tal ou qual grupo de alunos. Pois, como complementa Connell (2010), não precisamos de um retrato do "bom professor" no singular, mas retratos de "bons professores" no plural e do "bom ensino" no sentido coletivo. Precisamos de modelos de formação de professores que promovam práticas de ensino criativas, diversificadas e justas em um futuro educacional que almejamos como diferente do passado.

\section{REFERÊNCIAS}

ABRAMO, Helena. BRANCO, Pedro Paulo Martoni. Retratos da juventude brasileira. São Paulo: Perseu Abramo, 2005.

BARRĖRE, Anne e MARTUCELLI, Danilo. A escola entre a agonia moral e a renovação ética. Educação \& Sociedade,Campinas, ano XXII, no 76, Outubro/2001.

BARRÈRE, Anne. Les enseignants au travail. Routines incertaines. Paris, Edition L'Harmattan, 2002.

BRASIL. Lei de Diretrizes e Bases da Educação Nacional. Lei n 9394, de 20 de dezembro de 1996. 
. Ministério de Educação. Matriz de referência do novo Enem. Brasília, 2009. Ministério de Educação. Diretrizes Curriculares Nacionais para o Ensino Médio. Brasília. 2012.

BRENNER, Ana Karina e CARRANO, Paulo Cesar Rodrigues. Os sentidos da presença dos jovens no ensino médio: representações da escola em três filmes de estudantes. Educação \& Sociedade, Campinas, v. 35, n. 129, p. 1223-1240, out.-dez., 2016.

BRESSOUX, Pascal. As pesquisas sobre efeito-escola e efeito-professor. Educação em revista, Belo Horizonte, n. 8, dez. 2003.

BROOKE, Nigel \& SOARES, José Francisco. Pesquisa em eficácia escolar: origem e trajetórias. Belo Horizonte: Editora UFMG, 2008.

BRUNS, Barbara e LUQUE Javier. Professores excelentes: Como melhorar a aprendizagem dos estudantes na América Latina e no Caribe- Visão geral. Whashington: Grupo Banco Mundial, 2014.

CANÁRIO, Rui. A escola tem futuro? Das promessas as incertezas. Porto: Porto Editora, 2006.

CANDAU, Vera Maria (org.). A Didática em Questão. 17ª ed. Petrópolis: Vozes,1983.

, Vera Maria (org.). Rumo a uma Nova Didática. 22ª ed. Petrópolis: Vozes, 2012.

CARRANO, Paulo e DAYRREL, Juarez. Juventude e ensino médio: quem é este aluno que chega à escola. In: DAYRREL, Juarez; CARRANO, Paulo; e MAIA, Carla Linhares (org.) Juventude e ensino médio: sujeitos e currículos em diálogo. Belo Horizonte: Editora UFMG, 2014

CHARLOT, Bernard. Relação com o saber e com a escola entre estudantes de periferia. Cadernos de Pesquisa, São Paulo, n. 97, p. 47-63, maio 1996.

CONNELL, Raewyn. Bons professores em um terreno perigoso: rumo a uma nova visão da qualidade e do profissionalismo. Educação e Pesquisa, São Paulo, v. 36, n. especial, p. $165-184,2010$.

CUNHA, Maria Isabel da. 0 bom professor e sua prática.2 ed. São Paulo: Papirus, 182p.,1996.

DAYRELL, Juarez. A escola 'faz' as juventudes? Reflexões em torno da socialização juvenil. Educação \& Sociedade, Campinas, v.28, n.100, p. 1105-1128, out. 2007. 
DAYRELL, Juarez; CARRANO, Paulo; MAIA, Carla Linhares (organizadores). Juventude e ensino médio: sujeitos e currículos em diálogo. Belo Horizonte: Editora UFMG, 2014 DIAS, Amália. Apostolado cívico e trabalhadores do ensino: História do magistério do ensino secundário no Brasil (1931-1946). Dissertação de mestrado. Niterói: Universidade Federal Fluminense, p.251, 2008.

DUBET, François. A Sociologia da Experiência. Lisboa: Porto, 1994.

,François. Quando o sociólogo quer saber o que é ser professor. Entrevista com François Dubet, Rev. Bras. Educ. São Paulo, Set/Out/Nov/Dez 1997 № 6, 1997.

,François. El declive de la institución: profesiones, sujetos e individuos en la modernidad. Barcelona: Gedisa, 2002

,François. Sobre a Violência e os Jovens. Revista Especiaria. V.9. n.15, jan./jun.. p.11-31, 2006.

DUBET, François \& MARTUCCELLI, Danilo. A l'école: sociologie de l'experience scolaire. Paris: Éditions Seuil, 1996.

ELIAS, Norbert. A Sociedade dos Indivíduos. Rio de Janeiro: Jorge Zahar ed., 1994.

FANFANI, Emílio Tenti. Culturas jovens e cultura escolar. In: Seminário Escola Jovem: Um novo olhar sobre o Ensino Médio. Brasília: MEC, 2000.

FELIX Daniela Comassetto. $O$ bom professor na concepção do aluno: adolescentes em busca de um referencial adulto. Dissertação de mestrado. PUC-RS, Porto Alegre, 2009.

FERNANDES, Domingos. Avaliação de desempenho docente: Desafios problemas e oportunidades. Cacém: Texto editores, 2008.

FORMOSINHO, João. (Coord). Formação de professores. Aprendizagem profissional e acção docente. Porto: Porto Editora, 2009.

FORMOSINHO, João; MACHADO Joaquim e OLIVEIRA-FORMOSINHO, Júlia. Formação, Desempenho e Avaliação de Professores. Mangualde: Edições Pedago. 2010.

LESSARD, Claude. A universidade e a formação profissional dos docentes: novos questionamentos. Educação \& Sociedade, vol. 27, n.94, p.201-227, jan./abr. 2006.

MENDONÇA. Ana Waleska Pollo. A emergência do ensino secundário público no Brasil e em Portugal: uma "história conectada". Revista Contemporânea de Educação, Campos vol. 8, n. 15, 2013. 
MONTEIRO, Renata Gomes e MARTINS, Pura Lúcia Oliver. Quem é o bom professor para estudantes do ensino médio?In: In: IX Congresso Nacional de Educação_EDUCERE, PUC-Paraná, Curitiba, 2009.

NOGUEIRA, Daniele X. P., JESUS, Girlene R. e CRUZ, Shirleide P. S. Avaliação de desempenho docente no Brasil: desvelando concepções e tendências. Linhas Críticas, Brasília, vol. 19, núm. 38, pp. 13-32, 2013.

OCDE. Teachers Matter: Attracting, Developing and Retaining Effective Teachers. OECD, Paris. 2005.

OLIVEIRA, Rosiele Juvino. O Bom Professor de Matemática segundo a Percepção de Alunos do Ensino Médio. (Monografia). Universidade Católica de Brasília, 2007.

PERRENOUD, Philippe. Ensinar: agir na urgência, decidir na incerteza. $2^{\mathrm{a}}$ ed. Porto Alegre: Artmed, 2001.

REIS, Rosemeire. Experiência escolar de jovens/alunos do ensino médio: os sentidos atribuídos à escola e aos estudos. Educação e Pesquisa, São Paulo, v. 38, n. 03, p. 637-652, jul./set. 2012. RODRIGUES, Suely da Silva. Políticas de Avaliação Docente: tendências e estratégias. Ensaio: aval. pol. públ. Educ., Rio de Janeiro, v. 20, n. 77, p. 749-768, out./dez. 2012, SPOSITO, Marília P. Estudos sobre juventude e educação. Revista Brasileira de Educação. São Paulo, n. 5/6, p. 37-52, maio/dez. 1997.

Marília P. Algumas reflexões e muitas indagações sobre as relações entre juventude e escola no Brasil. In: ABRAMO, H. W.; BRANCO, P. P. M. (Orgs.). Retratos da juventude brasileira: análises de uma pesquisa nacional. São Paulo: Fundação Perseu Abramo, p. 87-127, 2005.

TARDIF, Maurice. Saberes docente e formação profissional. Petrópolis: Vozes, 2005.

TARDIF, Maurice; LESSARD, Claude. Trabalho docente: elementos para uma teoria da docência como profissão de interações humanas. Petrópolis: Vozes, 2005. 